\title{
A new strategy in neurocritical care nurse continuing stroke education: A hybrid simulation pilot study
}

\author{
Christopher Ryan Newey ${ }^{1}$, Robert Bell ${ }^{2}$, Melody Burks ${ }^{3}$, Premkumar Nattanmai ${ }^{4}$
}

${ }^{1}$ DO, MS, Assistant Professor of Neurology, Co-Director of Neurosciences Intensive Care Unit, Department of Neurology, University of Missouri, Columbia, Missouri, USA

${ }^{2}$ PA-C, Clinical Instructor of Surgery, Division of Neurosurgery, Department of Surgery, University of Missouri, Columbia, Missouri, USA

${ }^{3}$ Melody Burks, RN, Neurosciences Service Line Specialist, University Hospital, University of Missouri Health Care, Columbia, Missouri, USA

${ }^{4} \mathrm{MD}$, Assistant Professor of Neurology, Co-Director of Neurosciences Intensive Care Unit, Department of Neurology, University of Missouri, Columbia, Missouri, USA

\section{Type of article: Original}

\begin{abstract}
Introduction: High-fidelity simulation is frequently utilized in medical education. Its use in the neurosciences is limited by the inherent limitations of the manikin to simulate neurological changes. We report here the use of a hybrid simulation - a combination of lecture and high-fidelity manikin - in the education of neurosciences nurses, involved in care of neurocritical care patients.

Methods: Neurosciences nurses from at the University of Missouri, Columbia, MO, USA, which is an academic, tertiary-care medical center participated in the simulation during Spring of 2016. The simulation involved a patient presenting with acute intracerebral hemorrhage (ICH) who neurologically deteriorated to brain death. Preand post-simulation questionnaires were administered using a questionnaire with five-point Liker scale.

Results: Seventy-two responses were returned. The majority had 0-5 years of nursing experience with $83.8 \%$ having prior critical care experience. Pre-simulation, the majority of nurses $(85.7 \%)$ agreed or strongly agreed with managing patients with ICH. When the responses of "agree" were compared to "strongly agree", a significant improvement $(\mathrm{p}<0.001)$ in all responses except confidence in speaking with other healthcare providers was found.

Conclusion: Nurses reported significant improvement in understanding and managing patients with acute ICH and neurological deterioration after participating in a neurocritical care hybrid simulation. This study shows the benefit of using hybrid simulation in the education of neurocritical care nurses.

Keywords: Manikin, Critical care, Education, Cerebral hemorrhage
\end{abstract}

\section{Introduction}

Intensive care units are highly demanding work-environments requiring advanced skills to care for the critically-ill patient (1-7). Many of these skills are learned and maintained by repetition (1). Simulation has become an important tool in medical education for its ability to simulate real-life situations and create repetition. Simulation creates a learning environment that allows for improving technical and non-technical skills, improving efficiency, practicing rare life-threatening emergencies, and fostering improved attitudes toward teamwork (2). A well-known example that utilizes simulation is the certification and recertification of advanced cardiac life support (ACLS) (3). The maintenance of ACLS has been shown to be an important predictor in correctly managing patients in cardiac arrest $(1,4)$. In medical education, the use of simulation has also been shown to be effective in mimicking other real-life, medical scenarios in a safe environment (5-8). Additionally, the use of simulation with "sufficient realism to allow learners to suspend disbelief" in nursing education has been recognized to be an important method of educating

\section{Corresponding author:}

Assistant Professor Dr. Christopher Ryan Newey, 5 Hospital Drive, Columbia, MO 65212, Missouri, USA. Tel: +1-573-884-9582, Email: neweyc@health.missouri.edu Received: November 07, 2016, Accepted: January 18, 2017, Published: May 2017 iThenticate screening: January 18, 2017, English editing: February 21, 2017, Quality control: March 16, 2017 (C) 2017 The Authors. This is an open access article under the terms of the Creative Commons Attribution-NonCommercialNoDerivs License, which permits use and distribution in any medium, provided the original work is properly cited, the use is non-commercial and no modifications or adaptations are made. 
clinical scenarios $(2,9)$. In the medical education and residencies, the use of simulation has been used to bridge the gap between classroom and the clinical environment (1). At our tertiary level teaching hospital, we have recently appointed neurointensivists to manage the neurosciences intensive care unit (NSICU). As part of their appointment, an emphasis on nursing development has evolved. One such change is the utilization of a hybrid simulation - a combination of manikin simulation and video with lecture - to learn the basics of managing a patient with acute intracerebral hemorrhage $(\mathrm{ICH})$ who progressively deteriorates and eventually progresses to brain death. The hypothesis of this study was that neurocritical care nurses, after participating in the simulation, would feel more comfortable understanding and managing a patient with acute ICH that neurologically deteriorates.

\section{Material and Methods}

\subsection{Participants}

All neurosciences nurse $(\mathrm{n}=37)$ at the University of Missouri Health System, Columbia, MO, USA who are involved in the care of neurocritical care patients participated in this activity in the Spring of 2016. Incomplete surveys were excluded $(\mathrm{n}=2)$. No personal information was released. No compensation was provided for participating. The Institutional Review Board approved this project.

\subsection{Design}

As part of continuing nursing education, a hybrid simulation was created. Our hybrid simulation used a combination of lecture and simulation manikin. The simulation was a fictional patient named Ima B. Ailin. She was a 64 year-old lady admitted to the emergency department with acute stroke symptom of right arm and face weakness and dysarthria. Her National Institute of Health Stroke Scale (NIHSS) was 6; Glasgow Coma Scale (GCS) was 15, and blood pressure 180/90 with sinus rhythm on telemetry. She had a history of atrial fibrillation and was on coumadin. INR was 2.4. Computer tomography (CT) head on arrival showed a $3 \mathrm{cc} \mathrm{ICH} \mathrm{located} \mathrm{in} \mathrm{the} \mathrm{left} \mathrm{putamen.} \mathrm{At} \mathrm{this}$ point, the nurses were required to demonstrate and discuss as a group the clinical examinations important in stroke care. A discussion of localization of lesion, CT head interpretation, blood pressure control, and coagulopathy reversal then occurred through lectures. After a brief discussion on emergency management of an acute ICH, the patient was then admitted to the NSICU where her blood pressure acutely rose to $260 / 120 \mathrm{mmHg}$. Her examination then deteriorated to include right sided hemiplegia, right pupil enlargement (nonreactive) and hyperventilation. The hyperventilation and pupillary changes were seen on the simulation manikin. Her heart rate converted to a supraventricular tachycardia (SVT) with a rate of 179. The group was required to recognize the cardiac-brain code and begin resuscitation focused on the brain and the heart. A coma examination was then demonstrated by the teachers. We then discussed as a group the management of increased intracranial pressure. After the discussion, the patient had a CT head showing expansion of the ICH to 48cc. External ventricular device (EVD) waveform was shown on the monitor. We discussed setting up the EVD at bedside, waveform analysis, and nursing considerations for a patient with poor intracranial compliance (e.g., during bathing, travel). We returned to the patient whose exam acutely deteriorated. She then demonstrated brainstem areflexia and flaccid quadriplegia. The nurses were required to recognize the exam deterioration by bilateral nonreactive pupils, diabetes insipidus (simulated by foley bag with water), and hemodynamic instability. We performed a brain death examination together focusing on the complications that can occur during the testing/progression to brain death (e.g., arrhythmias, hypotension, and diabetes insipidus). After the simulation, a brief pre- and post-simulation survey was administered.

\subsection{Measures}

Demographic data was collected including age, gender, nursing experience, critical care nursing experience, and prior experience with simulation manikin. A confidential, voluntary survey was administered pre- and postsimulation asking nurses about their comfort level regarding patients with ICH. A five point Likert questionnaire using answers of "strongly disagree, disagree, neither disagree or agree, agree, and strongly agree". Descriptive statistics were performed on demographic data (using means and standard errors of the mean for continuous data and frequencies for categorical data) and on Likert-type data (median and frequencies). The Likert-type data was then grouped as agree (i.e., combination of strongly agree and agree) and disagree (i.e., combination of strongly disagree and disagree). Based on expected distribution of the unmatched data, we compared the groups "agree" to "strongly agree" based on distribution of responses. Chi-square statistics with Fisher's were used to analyze the data. A pvalue of $<0.05$ was considered significant. Data were analyzed using GraphPad Prism 7 (La Jolla, CA, USA).

\section{Results}

A total of 72 surveys ( 35 pre-simulation; 37 post-simulation) were completed from 37 nurses ( 33 female). The majority of participants were in the age range of 20 to 29 years $(59.5 \%)$. The majority of participants had a range of 
$0-5(70.2 \%)$ years of nursing experience and $83.8 \%$ with prior critical care nursing experience. The majority $(86.5 \%)$ had prior experience with simulation. Demographics of simulation participants can be found in Table 1 . The Likert-type data was grouped into "disagree" and "agree". For all six questions, the majority of nurses agreed with the responses pre- (65.7-85.7\%) and post- (81.1-91.9\%) simulation (Table 2A). Only $0-5.7 \%$ of responders disagreed to the responses pre-simulation and $2.7-8.1 \%$ post-simulation (Table 2A). None of the responses met statistical significance although a trend toward significance was seen on the question "I am prepared to care for real patients with intracerebral hemorrhage." Given the distribution of the responses toward agreement pre-simulation, the Likert-type data of "agree" and "strongly agree" were compared. On the pre-simulation responses, 57.1-68.6\% of responders agreed with the questions and $2.9-17.1 \%$ strongly agreed (Table 2B). Post-simulation, the responses increased to $40.5-56.8 \%$ agreement and $24.3-40.5 \%$ strongly agreed (Table 2B). Statistical significance was achieved in all but one question (Table 2B). This question was "I am confident in determining what to tell other healthcare providers when treating intracerebral hemorrhages."

Table 1. Participants' Demographics

\begin{tabular}{|l|l|l|l|}
\hline Variables & $\mathrm{n}$ & $\%$ \\
\hline Sex & Female & 33 & 89.2 \\
\cline { 2 - 4 } & Male & 4 & 10.8 \\
\hline Age Group (year) & $<20$ & 2 & 5.4 \\
\cline { 2 - 4 } & $20-29$ & 22 & 59.5 \\
\hline & $30-39$ & 5 & 13.5 \\
\cline { 2 - 4 } & $40-49$ & 3 & 8.1 \\
\hline & $50-59$ & 4 & 10.8 \\
\cline { 2 - 4 } & $60-69$ & 1 & 2.7 \\
\cline { 2 - 4 } & $>70$ & 0 & 0 \\
\hline Nursing Experience (year) & $0-5$ & 26 & 70.3 \\
\cline { 2 - 4 } & $6-10$ & 5 & 10.8 \\
\cline { 2 - 4 } & $11-15$ & 0 & 0 \\
\hline & $16-20$ & 2 & 5.4 \\
\cline { 2 - 4 } & $>21$ & 5 & 13.5 \\
\hline
\end{tabular}

Table 2. Nursing Reponses Pre- and Post-Simulation.

\begin{tabular}{|c|l|l|l|l|l|l|}
\hline \multicolumn{2}{|l|}{ A } & \multicolumn{2}{l|}{ Pre-Simulation } & \multicolumn{2}{l|}{ Post-Simulation } & p-value \\
\cline { 2 - 7 } \multicolumn{2}{|l|}{$\begin{array}{l}\text { I am prepared to care for real patients } \\
\text { with intracerebral hemorrhage }\end{array}$} & 0.0 & 85.7 & 5.4 & 81.1 & 0.06 \\
\hline 2) & $\begin{array}{l}\text { I have an understanding of the } \\
\text { pathophysiology of intracerebral } \\
\text { hemorrhage }\end{array}$ & 5.7 & 68.6 & 5.4 & 83.8 & 0.55 \\
\hline 3$)$ & $\begin{array}{l}\text { I have an understanding of the } \\
\text { medications used in treating intracerebral } \\
\text { hemorrhage }\end{array}$ & 5.7 & 68.6 & 8.1 & 86.5 & 1.00 \\
\hline 4) & $\begin{array}{l}\text { I am confident in my decision-making } \\
\text { and clinical skills when treating } \\
\text { intracerebral hemorrhages }\end{array}$ & 5.7 & 68.6 & 5.4 & 81.1 & 0.76 \\
\hline 5) & $\begin{array}{l}\text { I am confident in determining what to tell } \\
\text { other healthcare providers when treating } \\
\text { intracerebral hemorrhages }\end{array}$ & 5.7 & 65.7 & 2.7 & 81.1 & 0.31 \\
\hline 6$)$ & $\begin{array}{l}\text { I am confident that I will be able to } \\
\text { recognize and predict changes in my real } \\
\text { patient's condition }\end{array}$ & 2.9 & 85.7 & 5.4 & 91.9 & 0.72 \\
\hline
\end{tabular}




\begin{tabular}{|c|l|l|l|l|l|l|}
\hline \multicolumn{2}{|c|}{ B } & Pre-Simulation & Post-Simulation & \\
\cline { 3 - 7 } \multicolumn{2}{|l}{} & Agree (\%) & $\begin{array}{l}\text { Strongly } \\
\text { Agree (\%) }\end{array}$ & Agree (\%) & $\begin{array}{l}\text { Strongly } \\
\text { Agree (\%) }\end{array}$ & p-value \\
\hline 1$)$ & $\begin{array}{l}\text { I am prepared to care for real patients } \\
\text { with intracerebral hemorrhage }\end{array}$ & 68.6 & 17.1 & 40.5 & 40.5 & 0.0001 \\
\hline 2$)$ & $\begin{array}{l}\text { I have an understanding of the } \\
\text { pathophysiology of intracerebral } \\
\text { hemorrhage }\end{array}$ & 62.9 & 5.7 & 56.8 & 27.0 & 0.0001 \\
\hline 3$)$ & $\begin{array}{l}\text { I have an understanding of the } \\
\text { medications used in treating intracerebral } \\
\text { hemorrhage }\end{array}$ & 65.7 & 2.9 & 51.4 & 35.1 & 0.0001 \\
\hline 4$)$ & $\begin{array}{l}\text { I am confident in my decision-making } \\
\text { and clinical skills when treating } \\
\text { intracerebral hemorrhages }\end{array}$ & 57.1 & 11.4 & 43.2 & 37.8 & 0.0001 \\
\hline 5$)$ & $\begin{array}{l}\text { I am confident in determining what to tell } \\
\text { other healthcare providers when treating } \\
\text { intracerebral hemorrhages }\end{array}$ & 54.3 & 11.4 & 56.8 & 24.3 & 0.08 \\
\hline 6$)$ & $\begin{array}{l}\text { I am confident that I will be able to } \\
\text { recognize and predict changes in my real } \\
\text { patient's condition }\end{array}$ & 68.6 & 17.1 & 51.4 & 40.5 & 0.0004 \\
\hline
\end{tabular}

\section{Discussion}

The utilization of hybrid simulation models in NSICU nursing education has not been fully established. Our study is one of the first to incorporate hybrid simulation into the continuing education of neurocritical care nurses. Our study highlights that the majority of nurses agree or strongly agree with familiarity in managing patients with ICH. Additionally, our study shows that after participating in a hybrid simulation, nurses feel significantly more comfortable managing patients with ICH. Prior simulation models have been used in neurosciences medical education. A study by Hocker et al. used the simulation manikin to create a brain death scenario (5). Trainees from critical care medicine and neurology were required to perform a brain death examination on the manikin (5). This study found that only $71.5 \%$ of pre-requisites required for brain death testing were met, and only $71.0 \%$ of requirements of the clinical examination were achieved (5). The pre- and post-test assessment showed that the trainees' confidence significantly improved after simulation (5). Similarly, MacDougall et al. showed improvement in brain death determination after simulation (6). A study by Dworetzky et al. used simulation as part of seizure education in the epilepsy monitoring unit10. A combination of nurses and resident trainees participated (10). They found that after the simulation, knowledge in seizure management improved; however, confidence in managing seizure patient and improvement in clinical practice were not demonstrated (10). The study by Sperling et al. evaluated the use of simulation to teach students the clinical approach to altered mental status (11). Post-simulation participants reported improved differential diagnoses, diagnostic workup, and interventions needed in the first few minutes after recognizing altered mental status (11). These studies highlight the importance of simulation in education. Our data is comparable to the findings of these studies. After simulation, nurses reported feeling prepared and confident in managing a patient with acute ICH. Additionally, the nurses felt they had a better understanding of the pathophysiology of ICH and ultimately, felt more confident in recognizing acute neurological deterioration and management. Our data shows that despite the participation in the hybrid simulation, nurses continue to feel uncomfortable discussing ICH with other healthcare providers. This data is important and provides areas for process improvement. We plan to provide educational lectures on ICH with an emphasis on the relevant examination and scales/scores of ICH to address this finding. We chose the topic of ICH with acute neurological deterioration as our main teaching point for the neurocritical care nurses. The purpose of this simulation was not to teach how to perform and document a brain death examination. Rather, we aimed to focus on the acute management of a patient with an ICH and the recognition and management of worsening neurological examination and the nursing considerations during the neurological deterioration (e.g., hemodynamic instability, changes in examination, and diabetes insipidus). Simulations do have limitations. These include the time necessary to create a simulation scenario and the resources needed to host a simulation. Many scenarios were provided by manufacturers of the simulation manikin. However, these simulations were not neuro-specific and may not be up-to-date with current literature. Additionally, the manikins have limited capabilities of simulating neurological/neurosurgical emergencies. This limitation was overcome by creating a hybrid simulation as we have demonstrated. Hybrid simulation is a simulation that 
incorporates an actor/actress and PowerPoint information including videos and images. We plan to continue incorporating hybrid simulation into the education of the neurocritical care nurses. The education will be based on the topics from the Emergency Neurological Life Support (ENLS) created by the Neurocritical Care Society in 2015 (12). The purpose of ENLS is to educate the medical community on the management of the neurocritically ill patient in the first hour (12). Our NSICU is created to emphasize a multidisciplinary approach to the care of the patient. Nurses play a key role during bedside rounding. Nurses present information about the patient including data by organ system. This information is followed by the neuro-pharmacist reviewing the medications and finally the resident or mid-level provider discussing the plan of care. Improving nurses' knowledge of the pathophysiology and management of patients' critical illnesses, will only improve the quality of care provided.

\section{Conclusions}

Hybrid simulation using a combination of manikin and lecture can be used as a training tool in preparing participants to manage patients with a neurological emergency. Our data shows that nurses' self-reported knowledge in managing a simulated patient with a devastating spontaneous intracerebral hemorrhage, improved following a hybrid simulation course. We also found areas for process improvement following the simulation. Hybrid simulation is a useful method to train participants in neurological emergencies in a controlled setting. Future areas of research will evaluate the benefit of hybrid simulation in other neurological emergencies, such as acute ischemic stroke and status epilepticus, in the training of neurosciences nurses and resident physicians.

\section{Acknowledgments:}

The authors wish to acknowledge the University of Missouri neurosciences nurses for their participation in this exercise. We also wish to acknowledge the Russell D. and Mary B. Shelden Clinical Simulation Center at the University of Missouri, Columbia, MO, for their assistance in creating the simulation scenario.

\section{Conflict of Interest:}

There is no conflict of interest to be declared.

Authors' contributions:

All authors contributed to this project and article equally. All authors read and approved the final manuscript.

\section{References:}

1) Okuda Y, Bryson EO, DeMaria S Jr, Jacobson L, Quinones J, Shen B, et al. The utility of simulation in medical education: what is the evidence? Mt Sinai J Med. 2009; 76(4): 330-43. doi: 10.1002/msj.20127. PMID: 19642147.

2) Kim J, Park JH, Shin S. Effectiveness of simulation-based nursing education depending on fidelity: a metaanalysis. BMC Med Educ. 2016; 16: 152. doi: 10.1186/s12909-016-0672-7. PMID: 27215280, PMCID: PMC4877810.

3) American Heart Association. Advanced Cardiac Life Support. Available from: https://www.cpr.heart.org. Accessed 6/13/2016.

4) Schwid HA, O’Donnell D. Anesthesiologists' management of simulated critical incidents. Anesthesiology. 1992; 76(4): 495-501. doi: 10.1097/00000542-199204000-00002. PMID: 1550273.

5) Hocker S, Schumacher D, Mandrekar J, Wijdicks EF. Testing confounders in brain death determination: a new simulation model. Neurocrit Care. 2015; 23(3): 401-8. doi: 10.1007/s12028-015-0130-0. PMID: 25898887.

6) MacDougall BJ, Robinson JD, Kappus L, Sudikoff SN, Greer DM. Simulation-based training in brain death determination. Neurocrit Care. 2014; 21(3): 383-91. doi: 10.1007/s12028-014-9975-x. PMID: 24692109.

7) Dieckmann P, Lippert A, Glavin R, Rall M. When things do not go as expected: scenario life savers. Simul Healthc. 2010; 5(4): 219-25. doi: 10.1097/SIH.0b013e3181e77f74. PMID: 21330800.

8) Zigmont JJ, Kappus LJ, Sudikoff SN. The 3D model of debriefing: defusing, discovering, and deepening. Semin Perinatol. 2011; 35(2): 52-8. doi: 10.1053/j.semperi.2011.01.003. PMID: 21440811.

9) Waman KT, Nichols AA, O’Leary-Kelley C, Miller M. The evolution of a statewide network: the Bay Area Simulation Collaborative. Simul Healthc. 2011; 6(6): 345-51. doi: 10.1097/SIH.0b013e31822eaccc. PMID: 22157970.

10) Dworetzky BA, Peyre S, Bubrick EJ, Milligan TA, Yule SJ, Doucette H, et al. Interprofessional simulation to improve safety in the epilepsy monitoring unit. Epilepsy Behav. 2015; 45: 229-33. doi: 10.1016/j.yebeh.2015.01.018. PMID: 25812939. 
11) Sperling JD, Clark S, Kang Y. Teaching medical students a clinical approach to altered mental status: simulation enhances traditional curriculum. Med Educ Online. 2013; 18: 1-8. doi: 10.3402/meo.v18i0.19775. PMID: 23561054, PMCID: PMC3617787.

12) Neurocritical Care Society. Emergency Neurologic Life Support Series. Neurocrit Care. 2015; Suppl 2. Available from: https://www.enlsprotocols.org. Accessed 6/13/2016. 